\title{
Heart failure disease management program, its contribution to established pharmacotherapy and long-term prognosis in real clinical practice - retrospective data analysis
}

\author{
Marie Lazarovaa ${ }^{\mathrm{a},}{ }^{*}$, Dusan Lazar ${ }^{\mathrm{b}}$, Filip Malekc, Jan Vaclavik ${ }^{\mathrm{a}}$, Milos Taborsky ${ }^{\mathrm{a}}$, Andrew Ignaszewskid
}

\begin{abstract}
Background and Aims. The prognosis of patients with heart failure (HF) is still generally unfavorable. HF with reduced ejection fraction (HFrEF) patients reach target medication doses in very low percentages in daily clinical practice. HF disease management programs (DMP), including nurse and telemedicine support that facilitate achieving target medication doses, may improve the unfavorable prognosis.

Methods. We retrospectively analyzed the data of 738 patients with HFrEF who were followed in a single HF center during the years 1975-2011, for 6.4 (median) years. DMP, nurse and telemedicine support is established at this center. Results. The group achieved left ventricle (LV) recovery after the HF treatment. The median LV ejection fraction improved from $25.0 \%$ at baseline to $50.0 \%$ at the time of the latest data collection. The proportion of NYHA II, III and IV classes decreased from $27.6 \%, 30.2 \%$ and $29.7 \%$ to $26.6 \%, 7.2 \%$ and $0.1 \%$, respectively while the proportion of NYHA class I increased from $12.5 \%$ to $66.1 \%$. Median NT-proBNP decreased from 975.0 to $324.0 \mathrm{pg} / \mathrm{mL}$. The survival of the patient group was favorable; $79.7 \%$ survived 18.1 years after diagnosis of HF. A high percentage of the patients received recommended target or higher than target doses of angiotensin-converting enzyme inhibitors (82.0\%) and beta-blockers (78.1\%).
\end{abstract}

Conclusion. The established pharmacotherapy resulted from an effective DMP and this contributed to the favorable prognosis.

Key words: disease management program, heart failure, long term prognosis, pharmacotherapy dose

Received: July 23, 2018; Accepted with revision: September 21, 2018; Available online: October 5, 2018 https://doi.org/10.5507/bp.2018.059

(c) 2019 The Authors. This is an open access article licensed under the Creative Commons Attribution License (https://creativecommons.org/licenses/by/4.0/).

${ }^{a}$ Department of Internal Medicine I - Cardiology, University Hospital Olomouc and Faculty of Medicine and Dentistry, Palacky University Olomouc, Czech Republic

${ }^{b}$ Department of Biophysics, Faculty of Science, Palacky University Olomouc, Czech Republic

'Heart Failure Centre, Hospital Na Homolce, Prague, Czech Republic

${ }^{d}$ Department of Cardiology, Heart Function Clinics, St. Paul's Hospital, Vancouver, Canada

Corresponding author: Marie Lazarova, e-mail: marielazarova@seznam.cz

\section{INTRODUCTION}

Congestive heart failure $(\mathrm{CHF})$ is one of the most serious medical and socio-economic problems in the western world. It afflicts $1-2 \%$ of the population with a significant increase in prevalence in older age groups. According to the 2016 ESC Guidelines, an aging population along with the success of acute cardiovascular medicine leads to an increase in the prevalence of heart failure (HF $)^{1}$. The prognosis of HF patients, despite significant advances in care in recent decades, is still unfavorable. Up to half of the patients die within 5 years after CHF diagnosis ${ }^{1}$. In addition to the serious prognosis, morbidity is also an important issue for patients with HF. The course of the disease is accompanied by frequent re-hospitalizations for decompensation of HF which is associated with a significant worsening of the prognosis ${ }^{2}$.

Unfortunately, we know from clinical practice and the results of a number of registries that only a small pro- portion of patients are receiving the recommended $\mathrm{HF}$ disease modifying medication doses ${ }^{3-5}$. This unsatisfactory situation persists, despite the fact that the beneficial effect of treatment increases with dose ${ }^{6}$, especially so for beta-blockers ${ }^{7}$.

It has been repeatedly reported that a well-established Disease Management Program (DMP) for HF has significant potential to improve the prognosis of patients ${ }^{8-11}$. This is due to early diagnosis of HF, adequate patient education and the setting up of therapy according to Guidelines, including up-titration of pharmacotherapy with mortality benefit to target doses, if clinically feasible ${ }^{8-11}$.

In this paper, we describe a group of patients with $\mathrm{HF}$ with reduced ejection fraction $(\mathrm{HFrEF})$ who reached left ventricle (LV) recovery, long-term stabilization and showed good prognosis. We mainly analyzed the established pharmacotherapy with mortality benefit in this patient group. 
Table 1. Descriptive statistics and statistical comparison of obtained data.

\begin{tabular}{|c|c|c|}
\hline Parameter & Baseline characteristics & The latest data collection characteristics \\
\hline Age (median; $1^{\text {st_; }} 3^{\text {rd }}$-quartile) [years] & $55.0 ; 46.2 ; 64.2$ & $62.7 ; 53.4 ; 71.4$ \\
\hline Follow-up time (median; $1^{\text {st }} ; 3^{\text {rd }}$-quartile) [years] & \multicolumn{2}{|c|}{$6.4 ; 4.3 ; 9.8$} \\
\hline Male [\%] & \multicolumn{2}{|c|}{70.2} \\
\hline Female [\%] & \multicolumn{2}{|c|}{29.8} \\
\hline HF history - ICMP [\%] & \multicolumn{2}{|c|}{34.1} \\
\hline HF history - NICMP [\%] & \multicolumn{2}{|c|}{65.9} \\
\hline AH history [\%] & \multicolumn{2}{|c|}{52.2} \\
\hline DM history [\%] & \multicolumn{2}{|c|}{22.0} \\
\hline COPD history [\%] & \multicolumn{2}{|c|}{5.7} \\
\hline SVT history (atrial fibrillation or atrial flutter) [\%] & \multicolumn{2}{|c|}{33.1} \\
\hline NYHA: & \multicolumn{2}{|l|}{$* * *$} \\
\hline NYHA I [\%] & 12.5 & 66.1 \\
\hline NYHA II [\%] & 27.6 & 26.6 \\
\hline NYHA III [\%] & 30.2 & 7.2 \\
\hline NYHA IV [\%] & 29.7 & 0.1 \\
\hline Mitral regurgitation: & $* * * *$ & **** \\
\hline Mitral regurgitation $0[\%]$ & 27.0 & 55.4 \\
\hline Mitral regurgitation $1[\%]$ & 26.5 & 34.4 \\
\hline Mitral regurgitation $2[\%]$ & 21.2 & 8.1 \\
\hline Mitral regurgitation $3[\%]$ & 24.6 & 1.9 \\
\hline Mitral regurgitation $4[\%]$ & 0.6 & 0.1 \\
\hline LVEF (median; $1^{\text {st-; }} 3^{\text {rd }}$-quartile) [\%] & $25.0^{* * *} ; 20.0 ; 35.0$ & $50.0^{* * *} ; 40.0 ; 60.0$ \\
\hline LVEDD (median; $1^{\text {st-; }} 3^{\text {rd }-q u a r t i l e) ~[m m] ~}$ & $62.0^{* * *} ; 56.0 ; 67.9$ & $56.0^{* * *} ; 51.0 ; 62.0$ \\
\hline PASP (median; $1^{\text {st }} ; 3^{\text {rd }}$-quartile) $[\mathrm{mm} \mathrm{Hg}]$ & $39.0^{* * *} ; 31.0 ; 49.0$ & $31.0^{* * *} ; 26.0 ; 37.0$ \\
\hline BNP (median; $1^{\text {st }} ; 3^{\text {rd }}$-quartile) [pg/mL] & $324.0^{* * *} ; 90.0 ; 760.0$ & $83.0^{* * *} ; 32.8 ; 183.3$ \\
\hline NT-pBNP & $975.0^{* * *} ;$ & $324.0^{* * *} ;$ \\
\hline (median; $1^{\text {st }} ; 3^{\text {rd }}$-quartile) $[\mathrm{pg} / \mathrm{mL}]$ & $331.8 ; 2271.5$ & $120.0 ; 802.0$ \\
\hline $\begin{array}{l}\text { Systolic blood pressure } \\
\text { (median; } 1^{\text {st }} ; 3^{\text {rd }} \text {-quartile) }[\mathrm{mm} \mathrm{Hg}]\end{array}$ & NA & $113.0 ; 100.0 ; 130.0$ \\
\hline $\begin{array}{l}\text { Diastolic blood pressure } \\
\text { (median; } 1_{-}^{\text {st }} ; 3^{\text {rd }} \text {-quartile) }[\mathrm{mm} \mathrm{Hg}]\end{array}$ & NA & $69.0 ; 60.0 ; 78.0$ \\
\hline $\begin{array}{l}\text { Heart rate } \\
\left.\text { (median; } 1^{\text {st }} ; 3^{\text {rd }} \text {-quartile }\right)[\mathrm{L} / \mathrm{min}]\end{array}$ & NA & $66.0 ; 60.0 ; 72.0$ \\
\hline $\begin{array}{l}\text { Creatinine } \\
\left.\text { (median; } 1_{-}^{\text {st }} ; 3^{\text {rd }} \text {-quartile }\right)[\mu \mathrm{mol} / \mathrm{L}]\end{array}$ & NA & $94.0 ; 77.8 ; 114.0$ \\
\hline $\begin{array}{l}\left.\text { GFR (median; } 1^{\text {st }} ; 3^{\text {rd }} \text {-quartile }\right) \\
{\left[\mathrm{mL} /\left(\min 1.73 \mathrm{~m}^{2}\right)\right]}\end{array}$ & NA & $67.0 ; 54.0 ; 83.8$ \\
\hline $\mathrm{ICD}[\%]$ & NA & 26.2 \\
\hline CRT [\%] & NA & 11.8 \\
\hline
\end{tabular}

$* * *$ indicates statistically significant difference at $P<0.001$. NA means not-available.

\section{MATERIALS AND METHODS}

\section{Analysis Setting}

We analyzed a group of 738 patients with $\mathrm{HFrEF}$ who were followed at Heart Function Clinics, St. Paul's Hospital, Vancouver, Canada during the years 19752011.

A sophisticated DMP for HF with the significant involvement of nurses and telemedicine technologies is well established in the institution. Specialized HF nurses are involved in the education of patients, telephone consultations, telephone follow-ups, medication changes and up-titration according to the protocols. The nurses also do physical examination of patients and are involved in coordinating care.
The analyzed group of patients was transferred to the "maintenance" clinics according to the institutional protocol. These patients showed statistically significant improvement in NYHA class, degree of mitral regurgitation, LV ejection fraction (LVEF), left ventricular end diastolic diameter (LVEDD), pulmonary artery systolic pressure (PASP) (all four items classified by echocardiography), and BNP and NT-pBNP levels after HF treatment and clinical follow-up (see Table 1).

We retrospectively analyzed this group of "recovered" HF patients, especially the established pharmacotherapy with mortality benefit and we also assessed the survival of this selected patient group. We compared the data with registry data and HF clinical trial populations.

The retrospective data analysis was approved by the 
Table 2. Analysis of HF medical therapy at the time of the latest data collection.

\begin{tabular}{lr}
\hline ACEIs & \\
\hline Total [\%] & 60.8 \\
Within Total & \\
$\quad$ Ramipril [\%] & 88.9 \\
$\quad$ Perindopril [\%] & 5.6 \\
$\quad$ Quinapril [\%] & 2.7 \\
Trandolapril [\%] & 0.5 \\
Enalapril [\%] & 1.3 \\
Lisinopril [\%] & 0.4 \\
Accupril [\%] & 0.4 \\
Monopril [\%] & 0.2 \\
\hline ARBs & \\
\hline Total [\%] & 28.1 \\
Within Total & \\
Candesartan [\%] & 69.6 \\
Telmisartan [\%] & 7.2 \\
Losartan [\%] & 11.1 \\
Valsartan [\%] & 12.1 \\
\hline Beta-blockers & \\
\hline Total [\%] & 86.4 \\
Within Total & \\
Carvedilol [\%] & 3.2 \\
Bisoprolol [\%] & \\
Metoprolol Succinate [\%] & \\
Metoprolol Tartarate [\%] & 38.1 \\
Atenolol [\%] & 13.3 \\
\hline MRAs & \\
\hline Total [\%] & \\
Within Total & \\
Spironolactone [\%] & \\
Eplerenone [\%] & \\
\hline & \\
\hline
\end{tabular}

ethics committee of the first author's institution (reference number 42/18).

\section{Statistical Analysis}

Descriptive statistics were used on the patient baseline data and at time of the latest patient assessment. Patient data were obtained from the medical records of the clinics. Patients selected for the analysis were part of the "maintenance" clinics, where those with HF and long-term stabilization and improved clinical condition were transferred to. The primary data analysis was a description of the selected patient population. The pharmacotherapy at the latest data collection was also analyzed. The percentage of patients in selected drug groups (angiotensin converting enzyme inhibitors (ACEIs), angiotensin receptor blockers (ARBs), mineralocorticoid receptor antagonists (MRAs), beta-blockers) was analyzed. The percentage of each subgroup of medication was also assessed. We investigated the percentage of patients adjusted to target or even supramaximal doses of individual drugs and drug groups.

All interval data were first tested for normality using the Shapiro-Wilk test and all data failed $(P<0.001)$. Thus, they are described by medians, $1^{\text {st }}$ - and $3^{\text {rd }}$-quartiles. To evaluate statistically significant difference between paired baseline and the latest interval-type data, the Wilcoxon signed rank test was used, since differences in the paired data were not normally distributed $(P<0.05)$. This test was also used for finding statistically significant differences for ordinal data (New York Heart Association (NYHA) and mitral regurgitation classes). The Kaplan-Meier survival analysis with censored data was performed based on follow-up times determined from dates of the first (baseline) and the latest NYHA class determination. Excel (Microsoft) and SigmaPlot (Systat) were used for evaluation of the descriptive statistics and statistical testing.

\section{RESULTS}

\section{Patients Characteristics}

The group consisted of 738 HFrEF patients, median age 62.7 years at the date of latest data collection, of whom $70.2 \%$ were male and $29.8 \%$ female (see Table 1 ). The median patient follow-up time since diagnosis was 6.4 years with a minimum of 0.3 years and a maximum of 35.0 years. Throughout the observation period, the patients were hospitalized on average for 1.2 times for decompensated HF. Of these, $21.5 \%$ of patients were not hospitalized at all and $53.9 \%$ of patients only once. Etiologically, $65.9 \%$ of patients had non-ischemic cardiomyopathy (NICMP) and $34.1 \%$ ischemic cardiomyopathy (ICMP).

Patient comorbidities, such as arterial hypertension (AH), diabetes mellitus (DM), chronic obstructive pulmonary disease (COPD) and supraventricular tachycardia (SVT; atrial fibrillation or atrial flutter) are shown in Table 1. The table also shows NYHA classes (I, II, III, IV), mitral regurgitation classes $(0,1,2,3,4)$, LV ejection fraction (LVEF; during follow-up, median of the lowest LVEF was 22.0\%), left ventricular end diastolic diameter (LVEDD), pulmonary artery systolic pressure (PASP), BNP and NT-pBNP levels of the patients at baseline.

\section{Therapy}

Patients were adjusted to maximum doses of HF medication according to their tolerance, based on Guidelines recommendation. HF medication analysis was performed from the latest data collection - in the phase of stabilized disease. The percentage of patients treated with particular drug groups at the time of analysis as well as of each drug within a group is shown in Table 2.

$75.3 \%$ of patients on ACEIs were receiving ramipril target dose $10 \mathrm{mg}$ daily or higher, target dose of perindopril of $8 \mathrm{mg}$ per day and more had $3.3 \%$ of the ACEI patients, $2.5 \%$ of ACEI patients had quinapril target dose of $20 \mathrm{mg}$ per day and more, target dose of trandolapril of $4 \mathrm{mg}$ per day for $0.2 \%$ of ACEI patients, target dose of enalapril of $20 \mathrm{mg}$ per day and more had $0.7 \%$ of ACEI patients. Other ACEIs than recommended in the Guidelines were observed in the medication (see Table 2 ), as class effect is assumed and local habits must be taken into account.

As for ARBs, 23.2\% of ARB patients had a target dose 
of $32 \mathrm{mg}$ of candesartan per day or higher. $3.9 \%$ of ARB patients were on a dose of telmisartan of $160 \mathrm{mg}$ per day or greater. A target dose of losartan of $150 \mathrm{mg}$ per day or more was taken by $1.0 \%$ of ARB patients and a target dose of valsartan of $320 \mathrm{mg}$ daily by $3.9 \%$. ARBs were administered according to Guidelines except for a small number of patients receiving telmisartan, which was again due to local habits.

The most frequently used beta-blocker was carvedilol (see Table 2), as a target dose of $50 \mathrm{mg}$ daily or more in $40.6 \%$ of beta-blocker patients. A daily target dose of bisoprolol of $10 \mathrm{mg}$ or more and a metoprolol dose of 200 mg or more had $27.0 \%$ and $10.5 \%$ of beta-blocker patients, respectively.

In MRA therapy, a spironolactone target dose of 50 mg daily or more was used in only $1.1 \%$ of patients on MRA and $50 \mathrm{mg}$ daily or more of eplerenone, was taken by $0.5 \%$ of MRA patients.

If we count the percentage of patients who were on the target or higher doses of individual drug groups, we get the results shown Fig. 1. In relation to non-pharmacological treatment (see Table 1), 26.2\% of patients had an implantable cardioverter-defibrilator (ICD) and 11.8\% underwent cardiac resynchronization therapy (CRT).

\section{Evaluation of Prognostic Parameters}

Values for parameters obtained at the time of the latest data collection, when the disease was stabilized, reverse remodeling of the left ventricle (LV) was achieved and pharmacotherapy established, are summarized in Table 1.

\section{Mortality}

The results showed that $79.7 \%$ of the stabilized patient population survived 18.1 years after diagnosis was established (see Fig. 2).

\section{DISCUSSION}

We analyzed a group of HFrEF patients with improved and stabilized clinical condition and objectively accompanied by LV reversal remodeling (improvement in LVEF, decrease in LVEDD, degree of mitral regurgitation and pulmonary hypertension). Also improvement in NYHA class and decrease in natriuretic peptide levels was documented. All these changes were statistically significant (Table 1).

In our group of patients, there were mostly patients with NICMP (65.9\%), which is different from the standard population of HF patients and registry data where a higher proportion of patients with ICMP is found ${ }^{5}$. The patient population was rather young, with a median of 62.7 (mean 61.4) years at the latest data collection. For example, in the study IMPROVE HF, the average age was 71 years $^{12}$, in BIOSTAT-CHF the average age was 68 years ${ }^{7}$. This may be the reason for better co-operation and up-titration of medication compared with elderly patients. Also, the monitored patient population had fewer comorbidities than, e.g., the European Observation Program and the BIOSTAT-CHF study ${ }^{5,7,13}$, which may be another reason for better medication up-titration, better co-operation

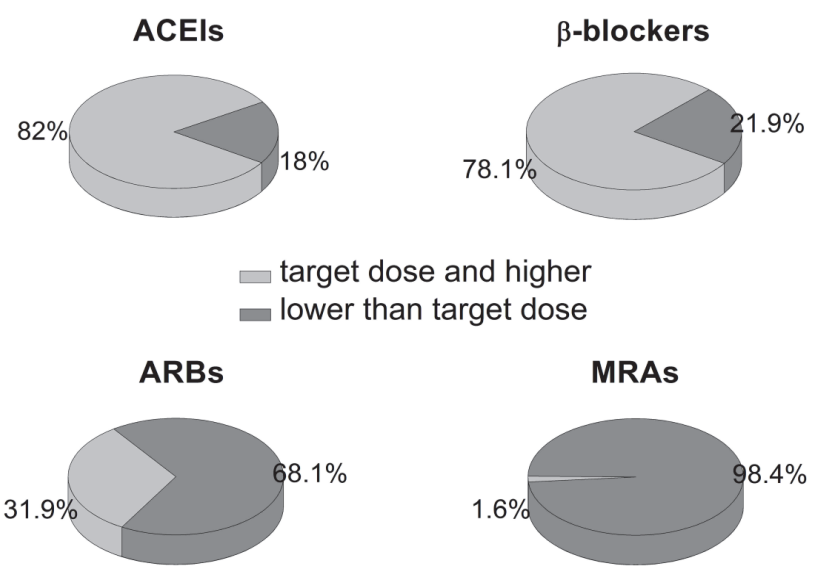

Fig. 1. Percentage of patients on target and higher than target dose of medication in each medication group (ACEIs, betablockers, ARBs, MRAs) at the time of the latest data collection.

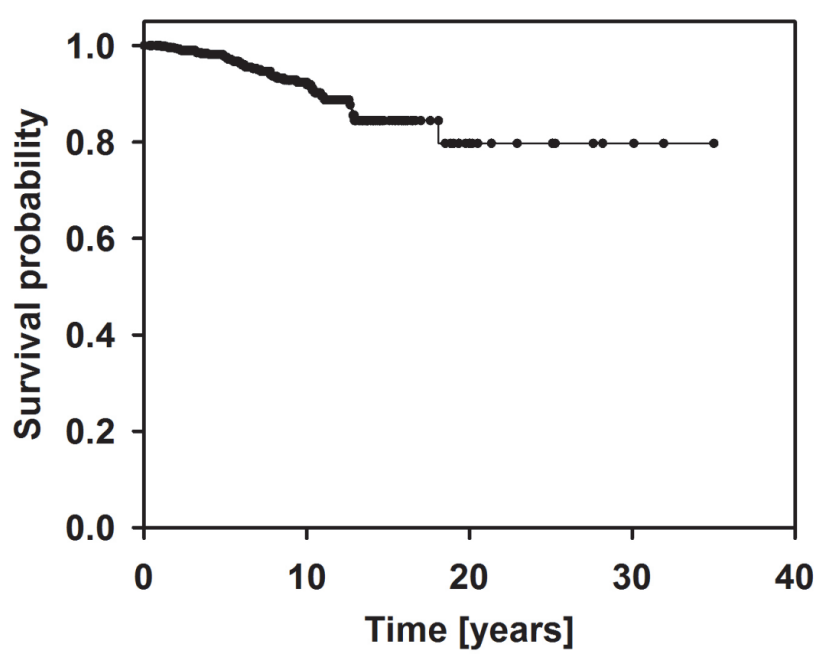

Fig. 2. Kaplan-Meier survival curve.

than in older polymorbid patients, and, of course, the reason for better prognosis.

The survival of our patient sample was much better than the general population of HF patients, where mortality is still $40-50 \%$ within 5 years after the diagnosis ${ }^{1}$.

One of the factors in the favorable prognosis of our patients was established pharmacotherapy (Fig. 1). For MRAs, only $1.6 \%$ of the patients were on the target or higher dose, however, it should be mentioned that the evaluation was performed at the time of improved LVEF. In addition, data supporting the administration of MRAs appeared for the first time in 1999 when RALES study was published, which, moreover, included only patients in functional NYHA classes III and IV (ref. ${ }^{14}$ ). In 2011, the results of EMPHASIS-HF study were published, which extended the administration of MRAs to patients in NYHA II functional class ${ }^{15}$. According to the PARADIGM-HF study published in 2014 , over $50 \%$ of patients had initial MRA treatment ${ }^{16}$. In this context, the low MRA representation in our patients is explainable. The change in treatment habits is also documented by the MERIT-HF initial medication analysis from 1999, where MRAs had 
not been monitored at all (and this was not required for inclusion), but $67 \%$ of patients had digoxin ${ }^{17}$.

With the exception of MRAs, the maximum medication doses in our case were comparable to those of clinical trials, where $49-84 \%$ of patients had target doses of ACEIs and ARBs and 66 - 80\% had target doses of beta-blockers $^{12}$. However, the reality of the common population of patients with HF is different in clinical practice. Comparison with real practice is the European HF registry, where target medication doses were achieved in the following percentages: $29.3 \%$ for ACEIs, $24.1 \%$ for ARBs, $17.5 \%$ for beta-blockers, and 30.5\% for MRAs (ref.5). According to other observational studies, only $5 \%$ of $\mathrm{HF}$ patients are at the target dose medication after hospitalization and $15 \%$ of HF patients are at the target dose of medication after a follow-up cardiologist visit ${ }^{4}$. However, for example, in the SHIFT study, where $90 \%$ of the patients had beta-blockers, the target dose was reached in only in $26 \%$ (ref. ${ }^{3,18}$ ). In particular, the maximal titration of beta-blocker therapy in our patient group is noteworthy ${ }^{7}$. A large percentage of our patients were at target and even supramaximal doses.

Proportional representation of groups of beta-blockers is also interesting. The most commonly used is carvedilol, which accounts for $45.1 \%$ from all beta-blockers. The target daily dose of $50 \mathrm{mg}$ and above included $40.6 \%$ of patients on beta-blockers. With bisoprolol were treated $38.1 \%$ of beta-blockers patients; a target daily dose of $10 \mathrm{mg}$ or more had $27.0 \%$ of beta-blocker patients. Metoprolol succinate medicated $13.3 \%$ of beta-blockers patients, with a target daily dose of $200 \mathrm{mg}$ and higher in $10.5 \%$ of beta-blocker patients. The use of beta-blockers for HF with reduced LVEF has very strong data on mortality reduction and certainly the most robust data in terms of target-specific mortality reduction ${ }^{6,7,19-22}$.

As mentioned above, nearly half of the patients treated with beta-blockers in our analysis are on carvedilol. Carvedilol, just like a non-selective $\beta 1, \beta 2$ and $\alpha$-adrenergic receptor blocker, has a remarkable position among beta-blockers indicated for HF. Instead, $\beta 1$ receptors are down-regulated in failing myocardium while the amount of $\beta 2$ receptors remains unchanged and the $\alpha 1$ receptors in the failing myocardium are increasing ${ }^{23}$. Also, adrenergic blockade caused by carvedilol, together with an antioxidant effect and increased insulin sensitivity, may play a positive clinical role in the patient improvement ${ }^{24}$. The antioxidant action of carvedilol reduces endothelial dysfunction and has antiapoptotic effect, which also has a favorable clinical impact on the progression of $\mathrm{HF}\left(\right.$ ref. $\left.^{19}\right)$. Combined alpha and beta blockade is more effective in reducing the toxic effect of catecholamines on myocardium and may contribute to a more significant reduction in mortality as clinically demonstrated in the COMET study, which resulted in a higher mortality reduction in HFrEF patients medicating carvedilol versus metoprolol ${ }^{19}$.

Limiting clinical condition for administration of the maximum dose of beta-blockers is in addition to the induction of hypotension and also an excessive drop in heart rate. In our group, with a high percentage of target betablocker doses, the median heart rate was $66.01 / \mathrm{min}$.
It is a question whether a group of patients achieving titration of medication to target doses is not primarily different and with primarily better prognosis. In patients who did not succeed in medication up-titration, their overall condition and comorbidities often prevent them from achieving higher doses (hypotension, renal insufficiency, mineral balance disturbances). Thus, in patients who are initially expected to have a better prognosis, therapy is better titrated to maximum and opposite.

On the other hand, there could be also a system error - patients are not up-titrated because of the absence of DMP. Limitations caused by the treating staff (acceptance of the results of clinical studies, knowledge of Guidelines and its transfer to practice, diligent work with the patient, explanation of individual steps, adequate education, cooperation of the whole team, etc.) can influence the situation. The institution at which the data analysis was performed has a very good system of care for HF patients (DMP) with a strong involvement of nurses, telemedicine technologies, protocols for medication up-titration.

Unfortunately, routine clinical practice in countries where DMP is not introduced leads to a significant number of HF patients who do not reach the target dose of medication, or who do not get recommended mediation at all ${ }^{25}$. One of the predictors of lower target doses of HF medication in the BIOSTAT-CHF study was country of inclusion ${ }^{7}$. Lower doses were found in Central and Southern Europe and higher are reported in patients from Scandinavian countries where DMP is common. The introduction of DMP may therefore increase the target beta-blocker dose from $10 \%$ to $43 \%$ due to frequent nurse control and up-titration therapy ${ }^{12}$. After the introduction of the telemetry titration protocol, $71 \%$ of patients achieved the target beta-blocker dose in 8 weeks ${ }^{12}$.

It is also necessary to mention the possibility of a higher frequency of LV recovery in patients with recently established non-ischemic dilated cardiomyopathy with potential myocarditis, but this was not determined bioptically or by MRI in this patient group ${ }^{26,27}$. The number of patients with NICMP was significantly higher in our sample than in other population of patients with cardiovascular disease, published studies, where, on the contrary, the ischemic etiology of HF predominates ${ }^{5,7}$. Interestingly, there were only $26.2 \%$ of patients with ICD and $11.8 \%$ of CRT in our sample. According to the guidelines, it is advisable to indicate CRT-D only after there is no improvement in the status following optimal drug therapy. Indications of ICD in patients with NICMP (65.9\% in the analyzed population), especially in the light of recently published data, is considerable ${ }^{28}$.

\section{Limitations}

The limitation of this study is that it is a retrospective data analysis of patients with no control group. Also, given the relatively long period of time (1975 - 2011), the results are influenced by changes in the diagnosis and treatment of HF. 


\section{CONCLUSION}

An established HF DMP with involvement of specialized nurses, telemedicine technologies and up-titration medication protocols positively affects a patient's prognosis. The selected group of HFrEF patients who achieved LV recovery had well-established HF pharmacotherapy achieving target medication doses in high percentage. This was especially evident for beta-blockers. Such a high percentage of HFrEF patients reaching target medication doses is unique in common clinical practice.

Author contributions: ML: data collection, data interpretation, manuscript writing; DL data analysis, statistical analysis, figures; AI and FM: study design; JV and MT: participation in revision of the manuscript.

Conflict of interest statement: None declared.

\section{REFERENCES}

1. Ponikowski P, Voors AA, Anker SD, Bueno H, Cleland JG, Coats AJ Falk V, González-Juanatey JR, Harjola VP, Jankowska EA, Jessup M, Linde C, Nihoyannopoulos P, Parissis JT, Pieske B, Riley JP, Rosano GM, Ruilope LM, Ruschitzka F, Rutten FH, van der Meer P. 2016 ESC Guidelines for the diagnosis and treatment of acute and chronic heart failure: The Task Force for the diagnosis and treatment of acute and chronic heart failure of the European Society of Cardiology (ESC). Developed with the special contribution of the Heart Failure Association (HFA) of the ESC. Eur J Heart Fail 2016;18(8):891-975.

2. Jencks SF, Williams MV, Coleman EA. Rehospitalizations among patients in the Medicare fee-for-service program. N Engl J Med 2009;360(14):1418-28.

3. Swedberg K, Komajda M, Böhm M, Borer JS, Ford I, Dubost-Brama A, Lerebours G, Tavazzi L. Ivabradine and outcomes in chronic heart failure (SHIFT): a randomised placebo-controlled study. Lancet 2010;376(9744):875-85.

4. Solal CA, Leurs I, Assyag P, Beauvais F, Clerson P, Contre C, Thebault JF, Genoun M. Optimization of heart FailUre medical Treatment after hospital discharge according to left ventricUlaR Ejection fraction: The FUTURE survey. Arch Cardiovasc Dis 2012;105(6-7):355-65.

5. Maggioni AP, Anker SD, Dahlstrom U, Filippatos G, Ponikowski P, Zannad F. Are hospitalized or ambulatory patients with heart failure treated in accordance with European society of cardiology guidelines? Evidence from 12440 patients of the ESC Heart failure long term registry. Eur J Heart Fail 2013;15(10):1173-84.

6. Packer M, Fowler MB, Roecker EB, Coats AJ, Katus HA, Krum H, Mohacsi P, Rouleau JL, Tendera M, Staiger C, Holcslaw TL, AmannZalan I, DeMets DL. Effect of Carvedilol on the Morbidity of Patients With Severe Chronic Heart Failure. Results of the Carvedilol Prospective Randomized Cumulative Survival (COPERNICUS) Study. Circulation 2002;106(17):2194-9.

7. Ouwerkerk W, Voors AA, Anker SD, Cleland JG, Dickstein K, Filippatos G. Determinants and clinical outcome of uptitration of ACEinhibitors and betablockers in patients with heart failure: a prospective European study. Eur Heart J 2017;38(24):1883-90.

8. Konstam MA, Konstam V. Heart failure disease management: a sustainable energy source for the health care engine. J Am Coll Cardiol 2010;56(5):379-81.

9. Inglis SC, Clark RA, McAlister FA, Stewart S, Cleland JG. Which components of heart failure programmes are effective? A systematic review and meta-analysis of the outcomes of structured telephone support or telemonitoring as the primary component of chronic heart failure management in 8323 patients: Abridged Cochrane review. Eur J Heart Fail 2011;13(9):1028-40.

10. Dreves HW, Steuten LMG, Lemmens LC, Baan CA, Boshuizen HC, Elissen AMJ, Lemmens KM, Meeuwissen JA, Vrijhoef HJ. The effectiveness of chronic care management for heart failure: meta-regression analyses to explain the heterogeneity in outcomes. Health Serv Research 2012;47(5):1926-59.
11. Cowie MR. The global relevance of disease management programmes for heart failure. Eur J Heart Fail 2014;16(9):927-8.

12. Gheorghiade M, Albert NM, Curtis AB, Thomas Heywood J, McBride ML, Inge PJ, Mehra MR, O'Connor CM, Reynolds D, Walsh MN, Yancy CW, Fonarow GC. Medication Dosing in Outpatients With Heart Failure after Implementation of a Practise-Based Performance Improvement Intervention: Findings From IMPROVE HF. Congest Heart Fail 2012;18(1):9-17.

13. Packer M, Poole-Wilson PA, Armstrong PW, Cleland JG, Horowitz JD, Massie BM, Rydén L, Thygesen K, Uretsky BF. Comparative Effects of Low and High Doses of the Angiotensin-Converting Enzyme Inhibitor, Lisinopril, on Morbidity and Mortality in Chronic Heart Failure. Circulation 1999;100(23):2312-8.

14. Pitt B, Zannad F, Remme WJ, Cody R, Castaigne A, Perez A. The effect of spironolactone on morbidity and mortality in patients with severe heart failure. N Engl J Med 1999;341(10):709-17.

15. Zannad F, McMurray JJ, Krum H, van Veldhuisen DJ, Swedberg K, Shi H, Vincent J, Pocock SJ, Pitt B. Eplerenone in patients with systolic heart failure and mild symptoms. N Engl J Med 2011;364(1):11-21.

16. McMurray JJ, Packer M, Desai AS, Gong J, Lefkowitz MP, Rizkala AR. Angiotensin-Neprilysin Inhibition versus Enalapril in heart failure. $\mathrm{N}$ Engl J Med 2014;371(11):993-1004.

17. MERIT-HF study group. Effect of metoprolol $C R / X L$ in chronic heart failure: Metoprolol CR/XL Randomised Intervention Trial in Congestive Heart Failure (MERIT-HF). Lancet 1999;353(9169):2001-7.

18. Braunwald E. Heart failure. JACC-Heart Fail 2013;1(1):1-20.

19. Poole-Wilson PA, Swedberg K, Cleland JG, Di Lenarda A, Hanrath P, Komajda M, Lubsen J, Lutiger B, Metra M, Remme WJ, Torp-Pedersen C, Scherhag A, Skene A. Comparison of carvedilol and metoprolol on clinical outcomes in patients with chronic heart failure in the carvedilol or metoprolol European Trial (COMET): randomised controlled trial. Lancet 2003;362(9377):7-13.

20. McAlister FA, Wiebe N, Ezekowitz JA, Leung AA, Armstrong PW. Metaanalysis: beta-blocker dose, heart rate reduction, and death in patients with heart failure. Ann Intern Med 2009;150(11):784-94.

21. Castagno D, Jhund PS, McMurray JJV, Lewsey JD, Erdmann E, Zannad F, Remme WJ, Lopez-Sendon JL, Lechat P, Follath F, Höglund C, Mareev V, Sadowski Z, Seabra-Gomes RJ, Dargie HJ. Improved survival with bisoprolol in patients with heart failure and renal impairment: an analysis of the cardiac insufficiency bisoprolol study II (CIBIS-II) trial. Eur J Heart Fail 2010;12(6):607-16.

22. Funck-Brentano C, van Veldhuisen DJ, van de Ven LL, Follath F, Goulder $M$, Willenheimer R. Influence of order and type of drug (bisoprolol vs.enalapril) on outcome and adverse events in patients with chronic heart failure: a post hoc analysis of the CIBIS-III trial. Eur J Heart Fail 2011;13(7):765-72.

23. Kveiborg B, Major-Petersen A, Christiansen B, Torp-Pedersen C Carvedilol in the treatment of chronic heart failure: Lessons from The Carvedilol Or Metoprolol European Trial. Vasc Health Risk Manag 2007;3(1):31-7.

24. Lechat $P$, Packer M, Chalon $S$, Cucherat M, Arab T, Boissel JP. Clinical effects of $ß$-adrenergic blockade in chronic heart failure. A meta-analysis of double-blind, placebo-controlled, randomized trials. Circulation 1998;98(12):1184-91.

25. Callender T, Woodward M, Roth G, Farzadfar F, Lemarie J-C, Gicquel S, Atherton J, Rahimzadeh S, Ghaziani M, Shaikh M, Bennett D, Patel A, Lam CS, Sliwa K, Barretto A, Siswanto BB, Diaz A, Herpin D, Krum H, Eliasz T, Forbes A, Kiszely A, Khosla R, Petrinic T, Praveen D, Shrivastava R, Xin D, MacMahon S, McMurray J, Rahimi K. Heart failure care in lowand middle-income countries: a systematic review and meta-analysis. PLos Med 2014;11:e1001699.

26. Krejci J, Hude P, Poloczkova H, Zampachova V, Stepanova R, FreibergerT, Nemcova E, Spinarova L. Correlations of the changes in bioptic findings with echocardiographic, clinical and laboratory parameters in patients with inflammatory cardiomyopathy. Heart Vessels 2016;31(3):416-26.

27. Krejci J, Hude P, Ozabalova E, Mlejnek D, Zampachova V, Svobodova I, Stepanova R, Spinarova L. Improvement of left ventricular systolic function in inflammatory cardiomyopathy: What plays a role? Biomed Pap-Olomouc 2016;160(4):524-32.

28. Køber L, Thune JJ, Nielsen JC, Haarbo J, Videbæk L, Korup E, Jensen G, Hildebrandt $\mathrm{P}$, Steffensen $\mathrm{FH}$, Bruun NE, Eiskjær $\mathrm{H}$, Brandes A, Thøgersen AM, Finn Gustafsson F, Egstrup K, Videbæk R, Hassager C, Svendsen JH, Høfsten DE, Torp-Pedersen C, Pehrson S. Defibrillator Implantation in Patients with Nonischemic Systolic Heart Failure. N Eng J Med 2016;375(13):1221-30. 